\title{
Management of the subsystem of production logistics in an enterprise
}

\author{
Marta Kadłubek ${ }^{1, *}$, and Agata Mesjasz-Lech ${ }^{1}$ \\ ${ }^{1}$ Czestochowa University of Technology, Faculty of Management, Al. Armii Krajowej 19 B, 42-200 \\ Częstochowa, Poland
}

\begin{abstract}
The logistic system emerged through the implementation of a systemic concept in logistics. In a production company the system can be very complex and it often consists of individual subsystems such as procurement and production subsystems. The article discusses the management of a logistic subsystem of production in terms of cost effectiveness on an example of a selected enterprise.
\end{abstract}

\section{Introduction}

Looking at the development of logistics so far one thing stands out. It is the shift in the focus of the concept - from sheer transformation of activities in the flow of goods towards an important and integrated concept of management which integrates and optimizes logistic systems. Systemic approaches determine different effects of thinking with logistic categories. Major emphasis is placed on the dimension of flow phases in a logistic system, where logistics is understood as a separate category of tasks within an enterprise [1]. Systemic references are key in distinguishing the logistic subsystem of production in an enterprise.

The logistic system of a company, including all logistic subsystems, should be effective. The concept of the effectiveness of a logistic system and its subsystems can be seen as a tendency to form a desired relationship between outlays and effects in the area of the system. The basic premise for the analysis of the effectiveness of a logistic system or its subsystems can be willingness of a business to improve its effectiveness.

The goal of the article is to present the aspects of the management of a logistic subsystem of production in terms of its effectiveness on an example of a selected business entity.

\section{The concept of production logistics in a logistic system}

The role of logistics in managing production is determined by its systemic interpretation. The range of application of the theories of systems reveals solid links with many fields of science, including logistics, which normalizes the basis for the determination of the notion of a logistic system. A systemic approach towards logistics enables enterprises to realize

\footnotetext{
* Corresponding author: martakadlubek@wp.pl
} 
many strategic tasks such as improving customer service in order to counterbalance the competitive edge of others or to maintain their own strong position on the market.

The logistic system of an enterprise can be very complex and consist of a number of subsystems such as the subsystem of procurement, production, distribution.

Scholars like: P. Blaik [2], G. Ghiani et al.[3], M. Nowicka-Skowron [4], H. Ch. Pfohl [5], indicate that the basic task of production logistics is twofold. On one hand it is the synchronization of the flow of goods (resources, semi-finished products, finished products) in the logistic system of an enterprise the moment they enter the enterprise, and on the other the creation of best possible environment for an effective planning and controlling production. Therefore, the subsystem of production logistics deals with all activities connected with the process of procurement of materials necessary for production and then moving the semi-finished products and finished products to the warehouse. The function of such a logistic activity in a company is increasing effectiveness of production processes, speeding up material flows and minimizing their cost. The subsystem of production logistics, which interfaces production technology and material procurement, is to reduce stock and improve customer service the through production of products in the right quantities, time and structure [6]. Production and logistic processes and activities are interrelated and often integrated.

In a systemic approach one must keep these relationships in mind when considering the cost effectiveness of the logistic system of an enterprise [2,4]. The evaluation of effectiveness is based on a global theory of systems which determines the search for a holistic concept of an effective organization of a given process or activity. The functional dimension of a system is examined in close consideration of the problems in the effectiveness of individual subsystems, including the subsystem of production. The starting point is distinguishing the tasks of the subsystem as a separate segment in the activity of the enterprise. The next sub-chapter presents the tasks of the production subsystem of the selected enterprise which later on are confronted with the notion of enterprise effectiveness.

\section{The subsystem of production logistics in the selected enterprise}

The chosen enterprise is a limited company - a production factory in the foundry industry [7]. The examined cast iron foundry has a machining division and an assembly line of cast iron products. The enterprise does both serial and custom production. It offers grey iron castings, cast iron radiators, household appliances, low voltage box-type switchboards, cast iron sewage splitters, and other products such as: cast iron stoves, elements of garden furniture, dumbbells, plant shelves, etc.

The activities in the subsystem of the production of manual meat mincers encompass the following:

- analyzing cast iron constructions in the light of technological requirements and the implementation of changes,

- determining the basic production parameters,

- dividing the system processes into operations and activities, organizing work and workstations,

- creating technological processes for the production of individual parts,

- determining time norms for the production of individual parts,

- developing temporary technical conditions for product acceptance,

- producing a sample batch for evaluation,

- performing an economic analysis of the production process,

- introducing changes to the construction and technology of individual parts, 
- making comparisons with the benchmark,

- developing the final technical conditions of acceptance.

The main task of the subsystem of production is to launch the production of new or modernized products technically similar to the ones produced in the world in a quick, proficient and economical way.

The initial stage of the process is control. It is realized through:

- checking the quality of procured input, moulding and auxiliary materials (e.g. chilled iron, hydrofluoric acid, coke, fluxes) as well as steel and tin,

- comparing the production quality with the current technical documentation,

- preventing shortages through identifying their causes and implementing solutions,

- initiating, coordinating and supervising the realization of all organizational and technical measures to improve the quality,

- controlling the quality and precision of technical support,

- controlling the precision of used machines and appliances.

The next stage is collecting raw materials for production and supplying them in right quantities to individual workstations. Production processes in the foundry, the hot galvanizing plant, the treatment plant and the tool shop necessitate moving considerable masses of different materials.

The majority of machines and appliances in the factory used in the production of manual meat mincers is also used for the production of other product. A significant part of the machinery for the production of mincers is also used in the production of different household appliances, cast irons, radiators, box-type switchboards, splitters, etc. Therefore the anticipated workload on some machines and appliances in the production of meat mincers is rather low which, however, does not mean they are unused. Considering the total production of the examined enterprise, the production capacity of the machinery is exploited in $90-95 \%$.

The number of machines and appliances necessary for the production of manual meat mincers was calculated on the basis of expected loads on machines and appliances with the volume of mincers production on the level of 279400 in 2017. The production structure in a technological view according to the number of machines, appliances and workstations is depicted in Figure 1.

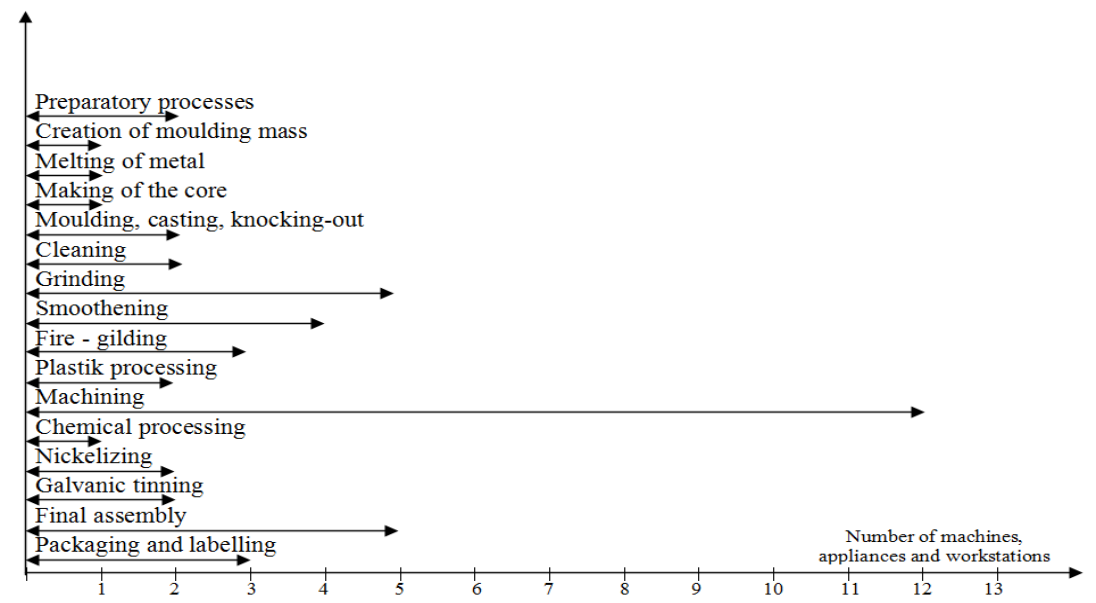

Fig. 1. The structure of the production of a manual meat mincer in a technological view according to the number of machines, appliances and workstations. 


\section{The model of production control for the analyzed enterprise}

Efficient and effective production is possible only if all necessary resources, including stock resources, are supplied. It should be pointed out that the analyzed enterprise is characterized by limited resources at the way in to the production logistics. The article suggests a SILSP (Single-item capacitated lot-sizing problem) mathematical model of production management. It's an LSP (Lot Sizing Problems) model for planning the size of a production batch which helps determine an optimal size of production realized for one product in a situation of demand intermittence and limited production resources [8]. The model was built for the enterprise described in the previous chapter. It will inform about the stock which should be procured for the production process and the number of products which should be made for further sales. This solution is to minimize the cost of both resource stock procurement and production processes with the use of the company's production factors. It will also reduce the cost of untapped output capacity. Therefore the function of the objective minimizes the total cost of the procurement of resources necessary for processing and production. Moreover, it was assumed that at the beginning and at the end of the discussed period the level of raw materials and finished products ready for warehousing is zero and the capacity for warehousing raw materials and distributional stock as well as processing capacity are the same in every period. The limiting conditions were:

- volume of output that can be achieved by the enterprise through the production process with the use of its own production factors in the analyzed period,

- capability to realize warehouse processes and utilize the space for storing products and materials,

- capability to realize production processes.

The model assumes the following decision-making variables:

- size of a given type of stock put through a production process,

- stock level of a product,

- size of a production batch,

- level of a given stock type,

- binary variables concerning the start of a production process,

- $\quad$ amount of a given stock type procured from suppliers.

All decision-making variables were applied to the discussed period which yields a dynamic representation of the problem. The mathematical formula of the model is as follows:

The function of objective:

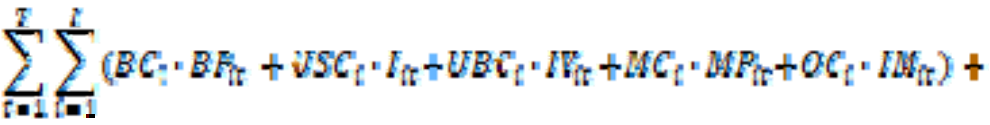

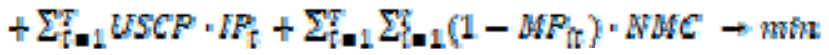

Conditions:

- connected with quantity of product obtained in the process of production:

$$
F P_{t}=\sum Q_{-1} P F_{t} \cdot M F_{\mathrm{t}} \quad \forall t_{t}
$$

onnected with level of given stock type:

$$
I_{h}=I_{b l-1}+I T_{t}-M P_{h t} \quad \forall w_{i} t
$$


onnected with level of product stock:

$$
I P_{\mathrm{t}}=I P_{\mathrm{t}-1}+P P_{\mathrm{t}}-D P_{\mathrm{t}}
$$

onnected with capabilities in terms of storage and production:

$$
\begin{array}{cc}
\sum_{l=1} A P \cdot I P_{t} \leq S P_{t} & \\
I P_{t} \leq S P_{t} & \forall t, t \\
I M_{t t} \leq D P_{t} & \forall t, t
\end{array}
$$

onnected with concordance of the result with regard to variables:

$$
\begin{aligned}
I W_{\mathrm{t}} \leq M & =M P_{\mathrm{it}} & \nabla_{i} t \\
W_{\mathrm{it}} \leq M & =B P_{\mathrm{t} t} & \forall t, t
\end{aligned}
$$

onnected with the type and sign of variables

$$
\begin{array}{cc}
M P_{\mathrm{ft}} B P_{\mathrm{t}} \in\{0,1\} & \forall t, t \\
I F_{\mathrm{i}}, I W_{t}, I_{\mathrm{i}} \geq 0 & \forall t, t \\
P P_{\mathrm{r}}, I F_{\mathrm{t}} \geq 0 & \forall t
\end{array}
$$

onnected with sets of objects:

Parameters:

$$
t=\{1,2 \ldots \ldots\} \quad t=\{1,2 \ldots, T\}
$$

$D P_{t}$ - required quantity of product in time $t$

$V P_{i}$ - quantity of product obtained from the processing of a stock unit $i$

$S P_{i}$ - capability to warehouse stock $i$

$M P_{i}$ - capabilities in terms of processing stock $i$

$A P$ - area taken by a unit of a product

$S P_{t}$ - capability to warehouse a product in period $t$

$U S C_{i}$ - unit cost of stock $i$ storage

$M C_{i}-$ cost of starting the process of stock $i$ processing

$O C_{i}$ - unit operational cost of processing stock $i$

$B C_{i}-$ cost of buying stock $i$

$U B C_{i}$ - unit cost of buying stock $i$

$U S C P$ - unit cost of product storage

$N M C$ - cost of untapped production capacity

Variables:

$I M_{i t}$ - quantity of stock $i$ to be processed in period $t$

$I_{i t}-$ level of stock $i$ in period $t$

$P P_{t}-$ quantity of product obtained in the process of production in period $t$

$I P_{t}-$ level of product stock in period $t$

$M P_{i t}$ - binary variable ( 1 - processing of stock $i$ in period $t$ is started, 0 - is not started)

$B P_{i t}$ - binary variable ( 1 - process of buying stock $i$ in period $t$ is started, 0 - is not started)

$I V_{i t}$ - quantity of stock i bought from suppliers in period $\mathrm{t}$. 
The function of objective (1) includes the cost of stock supply, cost of storage, cost of procurement of raw material stock, cost of starting production, operational cost of processing stock, cost of storage of a finished product, cost of untapped production capacity. Condition (2) determines the quantity of a product which can be obtained through processing of different stock types. Conditions (3) and (4) refer to the stock levels of raw material and finished product. Condition (5) provides assurance that the warehouse space occupied by the store does not exceed the available warehouse space. Condition (6) guarantees that the amount of products planned to be stored will not exceed the possibilities in this area. Condition (7) takes into account the limits for the processing of individual types of raw materials stock. Conditions (8), (9) guarantee the concordance of the result with regard to binary and decision-making variables. Conditions (10) - (12) are connected with the type of variables, and condition (13) determines the sets of objects considered in the model.

The proposed model considers the coordination of the processes of procurement logistics and production logistics. The level of raw material stock is determined by the demand for the product made of that material. Therefore, the model couples the processes of procurement and production. This means it is a solution which considers the needs of the enterprise in terms of stock according to the demand for the product and the output capacity of the enterprise which gives flexibility in the control of stock levels of raw materials.

\section{Conclusions}

To conclude on the topic of logistic systems it should be underlined that their scope extends from the issues of procurement all the way to the consumption of a product. The multiplicity of systems is determined by the perspective of logistics and the issues it deals with. A systemic approach towards the activity of businesses is characterized by a holistic look at the problems and an analysis of the importance of individual elements of systems (subsystems) and their relationships.

Activities realized in the framework of production logistics should be focused not only on ensuring the efficiency of the production system, but on its effectiveness in the first place. The proposed model considers all aspects of the functioning of production logistics: efficiency, proficiency and cost-effectiveness.

\section{References}

1. P.M. Price, N.J. Harrison, Looking at logistics: a practical introduction to logistics, customer service, and supply chain management (Access Education, United Kingdom, 2013)

2. P. Blaik, Efektywność logistyki. Aspekt systemowy i zarządczy (PWE, Warszawa, 2015)

3. G. Ghiani, G. Laporte, M. Musmanno, Introduction to logistics systems management (Wiley-Blackwell Pub., New Jersey, 2013)

4. M. Nowicka-Skowron, Efektywność systemów logistycznych (PWE, Warszawa, 2001)

5. H. Ch. Pfohl, Logistiksysteme (Springer Berlin Heidelberg, Berlin, 2010)

6. D. Bowersox, D. Closs, M.B. Cooper, Supply Chain Logistics Management (Mc Graw-Hill, United States, 2012)

7. M. Nowicka-Skowron, R. Ulewicz, METAL 2015: 24th International Conference On Metallurgy And Materials, 1707-1712, (2015)

8. N. Brahimi, N. Absi, S. Dauzere-Peres, A. Nordli, European Journal of Operational Research, 263(3), 838-863 (2017) 